\title{
Survival of Lactobacillus Isolates From Industrial Byproducts of Fruits To Different pH Conditions and Their Potential Probiotic Properties.
}

Estefânia Fernandes Garcia (I), Danilo Elias Xavier (I), Winnie Alencar Luciano (I), Rayssa Julliane de Carvalho (I), Marciane Magnani (I), Maria Saarela (II), Evandro Leite de Souza (I)

(I) UFPB - Federal University of Paraíba (Cidade Universitária - João Pessoa - PB - Brasil CEP: 58051-900), (II) VTT TRCF - VTT Technical Research Centre of Finland (PO Box 1000, 02044 VTT, Finland)

\section{Resumo}

Lactobacillus spp. are generally adapted to low $\mathrm{pH}$ environments, such as gastrointestinal tract. This is one of several essential characteristics of microorganisms added into food as probiotics. The aim of this work was to isolate potential probiotic strains from industrial byproducts of fruits. A total of 305 lactic acid bacteria (LAB) strains were isolated from byproducts of guava pulp, acerola, soursop, mango and strawberry. Fiftytwo were identified using MALDI-TOF technique (MALDI Biotyper Bruker) as Lactobacillus fermentum $(n=21)$, L. plantarum $(n=11), L$. brevis $(n=2)$ and L. nagelii $(n=8)$, L. paracasei $(n=2)$ and Lactobacillus spp. $(\mathrm{n}=8)$. Nineteen selected strains was evaluated for in vitro acidic tolerance. Briefly, stationary-phase-grown cells were harvested, washed with PBS and suspended (ca. 8-9 log CFU $\times \mathrm{mL}-1$ ) in $1 \mathrm{~mL}$ of PBS. A 7-8 $\log$ CFU $\times m L-1$ bacterial suspension was inoculated into PBS with final $\mathrm{pH}$ adjusted to 2.0, 3.0, 5.0 and 7.2 and incubated at $37^{\circ} \mathrm{C}$ for 15,120 and 180 min. For each condition, viable cell counting was determined by microdrop colony count technique on MRS agar plates incubated at $37^{\circ} \mathrm{C}$ for $48-72 \mathrm{~h}$ under anaerobic condition. Among the tested strains, L. fermentum and L. plantarum exhibited the highest tolerance to acidic condition. Both tested species could be recovered after exposing to $\mathrm{pH} 2.0$ and 3.0 during 15 and 
$180 \mathrm{~min}$, respectively. However, L. nagelii, L. brevis and L. paracasei strains were not recovered after exposing for $15 \mathrm{~min}$ at $\mathrm{pH}$ 2.0. While $\mathrm{L}$. brevis and L. paracasei were tolerant even after $180 \mathrm{~min}$ of exposing at $\mathrm{pH}$ 3.0, 5.0 and 7.2, colony counting of L. nagelii exhibited a 2-log reduction after $180 \mathrm{~min}$ of exposing at $\mathrm{pH} 5.0$ compared to initial inoculum. Despite

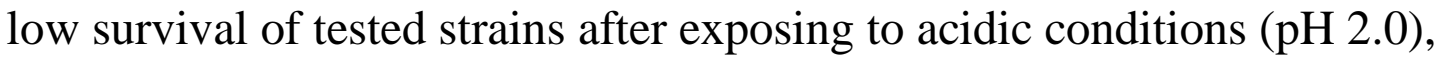
all evaluated strains were tolerant to acidic conditions compatible with the majority of food matrices, demonstrating potential use as starter culture or probiotic strains on these substrates.

Palavras-Chave: probiotics, functional food, MALDI-TOF Agência de Fomento: $\mathrm{CNPq}$ 